\title{
Sodium Bis(oxalato)borate in Trimethyl Phosphate: A Fire- Extinguishing, Fluorine-Free, and Low-Cost Electrolyte for Full-Cell Sodium-Ion Batteries
}

\author{
Ronnie Mogensen, Simon Colbin, Ashok Sreekumar Menon, Erik Björklund, and Reza Younesi*
}

Cite This: ACS Appl. Energy Mater. 2020, 3, 4974-4982

Read Online

ACCESS | Llll Metrics \& More | 国 Article Recommendations | sl Supporting Information

ABSTRACT: Sodium-ion batteries based on all-naturally abundant elements, in which no cobalt, nickel, copper, and fluorine is used, can lead to a major breakthrough in making batteries more sustainable. Safety aspects-in particular, flammability of electrolytes - in the state-of-the-art battery technology is another important concern, especially for applications in which large numbers of cells are employed. Nonflammable battery electrolytes studied so far are based on highly fluorinated compounds or high salt concentrations, which suffer from high cost and toxicity. We

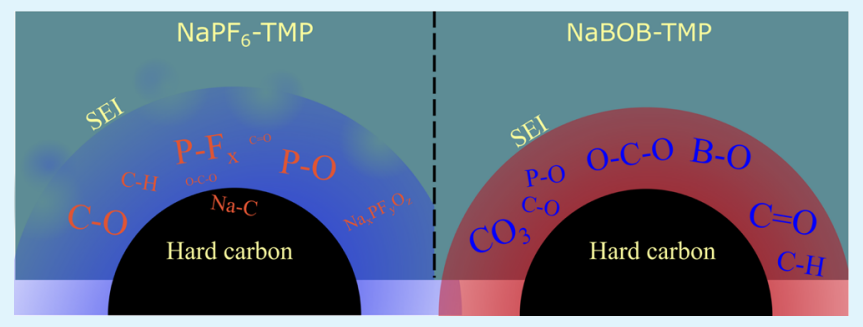
here propose an electrolyte based on a single solvent and low-cost and fluorine-free salt at a lower range of "standard" concentrations. Our results show-for the first time-that sodium bis(oxalato)borate ( $\mathrm{NaBOB}$ ) is soluble in the nonflammable solvent trimethyl phosphate (TMP). This finding enables a nonflammable electrolyte with high ionic conductivity and promising electrochemical performance in full-cell sodium-ion batteries. An electrolyte of $0.5 \mathrm{M} \mathrm{NaBOB}$ in TMP provides an ionic conductivity of $5 \mathrm{mS} \mathrm{cm} \mathrm{cm}^{-1}$ at room temperature, which is comparable to the commonly used electrolytes based on sodium hexafluorophosphate $\left(\mathrm{NaPF}_{6}\right)$ and organic carbonate solvents. The proposed electrolyte shows a Coulombic efficiency of above $80 \%$ in the first cycle, which increased to about $97 \%$ from the second cycle in sodium-ion battery full-cells consisting of a hard carbon anode and a Prussian white cathode. This work opens up opportunities to design safe electrolytes which can further be optimized with electrolyte additives such as vinylene carbonate for industrial applications.

KEYWORDS: electrolyte salt, non-flammable, fire-retardant, hardcarbon, full-cell, Na-ion battery, TMP, NaBOB

\section{INTRODUCTION}

Sodium-ion batteries have been proposed to provide a more sustainable battery system compared to lithium-ion battery technology, facilitating the use of rechargeable high energy density batteries for large scale applications such stationary storage. ${ }^{1-4}$ This is particularly achievable if cells contain only naturally abundant elements and by eliminating, among others, cobalt, nickel, and copper. Safety is another important concern for large scale applications, and in this respect, the flammability of the nonaqueous electrolytes may limit the use of the stateof-the-art battery technology in some applications. ${ }^{5,6}$

Most electrolytes used for sodium-ion batteries today are based on the same formula as the lithium-ion counterparts using organic carbonate solvents. ${ }^{7}$ It should also be noted that the electrolyte composition is a concern for sustainability because the electrolytes used in both sodium- and lithium-ion batteries employ fluorinated salts such as sodium hexafluorophosphate ( $\left.\mathrm{NaPF}_{6}\right)$ and sodium bis (trifluoromethanesulfonyl)imide (NaTFSI) which are toxic and expensive to produce. ${ }^{3,8}$

Here, we address both issues of the sustainability and safety of modern batteries by presenting a fluorine-free and nonflammable electrolyte for use in sodium-ion batteries.
The proposed electrolyte is based on sodium bis(oxalato)borate $(\mathrm{NaBOB})$ salt and trimethyl phosphate (TMP) as the sole solvent. Since its synthesis and characterization by $\mathrm{Xu}$ and Angell, ${ }^{9} \mathrm{LiBOB}$ has been used with great success in lithium-ion batteries, both as a stand-alone salt ${ }^{10-15}$ and additive. ${ }^{16-18}$ $\mathrm{NaBOB}$, however, first synthesized by Zavalij et al. ${ }^{19}$ in 2003, has been considered insoluble in organic solvents to be used in practice. Thus, salts such as sodium-difluoro(oxalato)borate $(\mathrm{NaDFOB})^{20}$ as well as other functionalized versions of $\mathrm{NaBOB}^{21}$ have been developed to address this. In this work, we show the first example of a suitably conductive NaBOBbased electrolyte cycled in full-cell sodium-ion batteries with hard carbon anodes and Prussian white cathodes. The results are compared with $\mathrm{NaPF}_{6}$ in TMP electrolytes with and without additives.

Received: March 11, 2020

Accepted: April 22, 2020

Published: May 5, 2020 

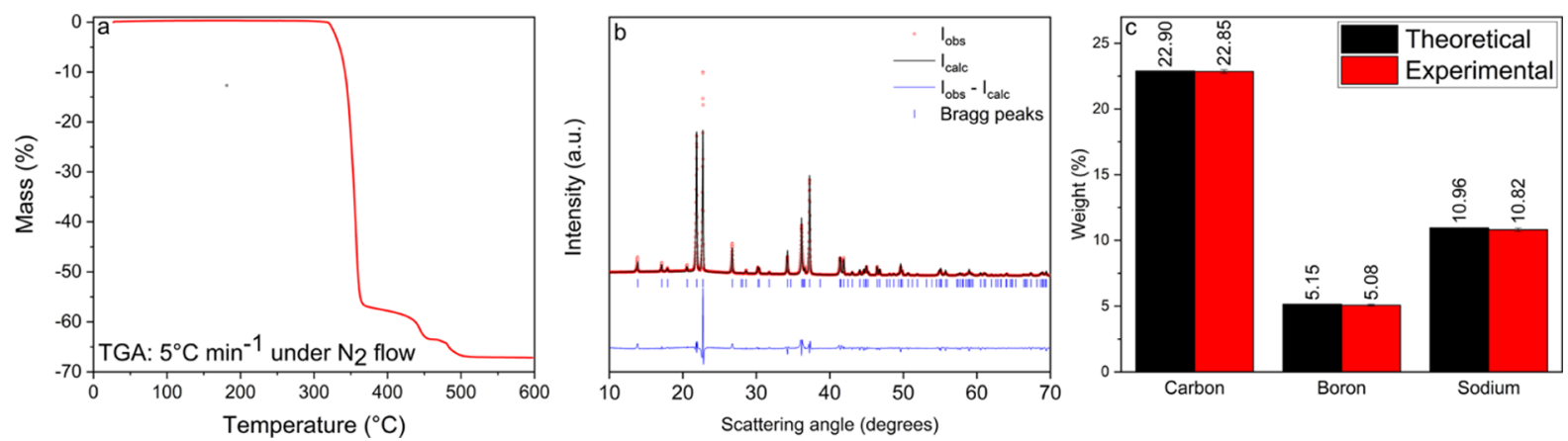

Figure 1. TGA results showing thermal stability of $\mathrm{NaBOB}$ in nitrogen gas at $5{ }^{\circ} \mathrm{C} \mathrm{min}^{-1}$ heating rate (a) and Rietveld refinement of the $\mathrm{NaBOB}$ powder X-ray diffraction data (b). Results from the ICP-OES and combustion analysis of the NaBOB powder used for the electrolytes (c).

TMP has previously been shown to reduce the flammability of electrolytes and therefore has been used as a cosolvent together with flammable solvents such as ethylene carbonate and propylene carbonate (PC). ${ }^{22-25} \mathrm{TMP}$ as a sole solvent suffers the major shortcoming of poor electrochemical stability, especially when using hard carbon anodes for sodium ${ }^{24}$ or graphite anodes for lithium ${ }^{26,27}$ because of insufficient anode passivation. This problem has been overcome in other studies by using highly concentrated electrolytes based on $\mathrm{NaN}$ $\left(\mathrm{SO}_{2} \mathrm{~F}\right)_{2}(\mathrm{NaFSI}), \mathrm{LiN}\left(\mathrm{SO}_{2} \mathrm{~F}\right)_{2}(\mathrm{LiFSI})$, and $\mathrm{LiN}\left(\mathrm{SO}_{2} \mathrm{C}_{2} \mathrm{~F}_{5}\right)_{2}$ (LiBETI) salts. ${ }^{26-29}$ While highly concentrated electrolytes can combine good cyclability and safety, they do have some detrimental attributes such as low ionic conductivities, high viscosity, and furthermore, high cost due to the large quantity of fluorinated salts.

Here, we, for the first time, show that the combination of a relatively low concentration of $\mathrm{NaBOB}$ salt $(0.5 \mathrm{M})$ with TMP provides remarkably stable cycling, demonstrating a very promising low-cost and green battery chemistry.

\section{RESULTS AND DISCUSSION}

"Structure, Conductivity, and Flammability". The synthesis and structural properties of $\mathrm{NaBOB}$ has previously been investigated by Zavalij et al., ${ }^{19}$ and their work provided a good foundation for the synthesis and determination of the purity of the NaBOB. LiBOB performance is sensitive to impurities, ${ }^{17}$ and therefore, $\mathrm{NaBOB}$ was recrystallized in TMP in our work. Figure 1 shows X-ray diffraction, elemental analysis, and thermogravimetric analysis (TGA) of $\mathrm{NaBOB}$ salt synthesized in this work. The combined results from X-ray diffraction (XRD) and elemental analysis based on combustion analysis and inductively coupled plasma (ICP)-optical emission spectroscopy (OES) show that the salt has high purity as proven by the stoichiometry. No impurity phase was detected in the diffractogram (see Tables S1 supplemental for XRD analysis details). The TGA results indicate that $\mathrm{NaBOB}$ salt is stable up to $300{ }^{\circ} \mathrm{C}$ in nitrogen, which is an important advantage compared to $\mathrm{NaPF}_{6}$ being stable up to $140{ }^{\circ} \mathrm{C}$ under vacuum. $^{30}$

Figure 2 shows that the ionic conductivity of $\mathrm{NaBOB}-\mathrm{TMP}$ increases with $\mathrm{NaBOB}$ concentration, ultimately reaching $5 \mathrm{mS}$ $\mathrm{cm}^{-1}$ for $0.5 \mathrm{M} \mathrm{NaBOB}$ in the TMP electrolyte at room temperature, which is similar to the corresponding ionic conductivity of $6 \mathrm{mS} \mathrm{cm} \mathrm{cm}^{-1}$ for $1 \mathrm{M} \mathrm{NaPF}_{6}$ in TMP. These values are within the range of ionic conductivity of practical nonaqueous electrolytes based on carbonates. ${ }^{31}$ The maximum concentration of $\mathrm{NaBOB}$ in TMP, that is $0.5 \mathrm{M}$, was achieved as a clear solution after both heating and rigorous stirring while

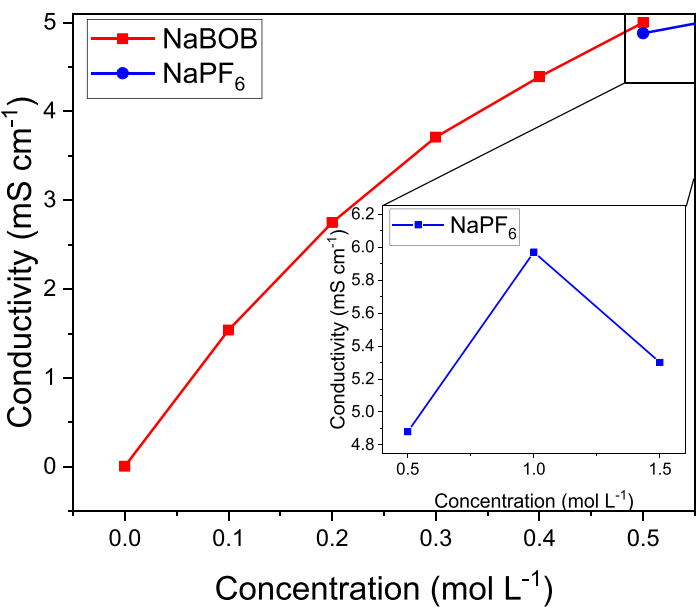

Figure 2. Ionic conductivity data for solutions containing $\mathrm{NaBOB}$ and $\mathrm{NaPF}_{6}$ dissolved in TMP. The measurements were performed at room temperature $\left(\sim 22^{\circ} \mathrm{C}\right)$.

a 0.6 M sample remained turbid after an identical treatment. This lower concentration of $0.5 \mathrm{M} \mathrm{NaBOB}$ compared to conventional electrolytes based on $1 \mathrm{M} \mathrm{NaPF}_{6}$ is in favor of reducing the electrolyte cost. In addition, the raw materials used for the synthesis of $\mathrm{NaBOB}$ are common and benign compared to the raw materials used in the production of the $\mathrm{PF}_{6}{ }^{-}$salts ${ }^{32}$ such as $\mathrm{HF}, \mathrm{PCl}_{5}$, and fluorine gas. Furthermore, the synthesis procedure for $\mathrm{NaBOB}$ is facile, safe, and does not require an inert environment.

Flammability tests were performed using a butane lighter in order to verify that the addition of $\mathrm{NaBOB}$ does not change the flammability properties of the TMP solvent. TMP did not ignite for any concentration of $\mathrm{NaBOB}$ (see Videos $\mathrm{S} 1-\mathrm{S} 3$ in the Supporting Information), while a reference sample consisting of PC showed a strong self-propagating flame. Immediately upon removal of the flame source from the $\mathrm{NaBOB}-\mathrm{TMP}$ samples, all traces of fire disappeared, thus making it impossible to determine a self-extinguishing time. In contrast, PC burnt vigorously until entirely consumed using the same experimental setup (see Figure 3).

"Electrochemical Performance". Cyclic voltammetry (CV) experiments in Figure $4 \mathrm{a}$ show that $\mathrm{NaBOB}$ undergoes reduction starting at $1.6 \mathrm{~V}$ versus $\mathrm{Na}^{+} / \mathrm{Na}$ in the first scan. However, as cycling progresses, effective passivation becomes evident as the reduction current significantly decreases. CV also shows oxidation current at $3 \mathrm{~V}$ in the first scan which can be decomposition of some reduction product during the first cycle. The stability however extends to approximately $4 \mathrm{~V}$ after 


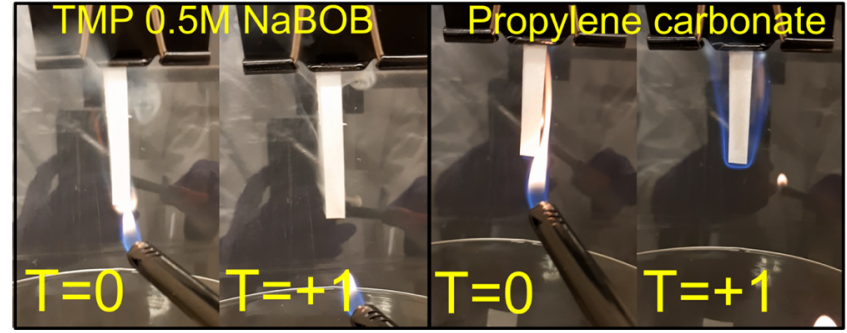

Figure 3. Flammability tests for TMP $0.5 \mathrm{M} \mathrm{NaBOB}$ (left) and PC (right). " $T$ " indicates time in seconds passed between frames.

the first cycle. Figure $4 \mathrm{~b}$ displays $\mathrm{CV}$ of $1 \mathrm{M} \mathrm{NaPF}_{6}$ in TMP, where the reduction starts at $1 \mathrm{~V}$ in the first sweep, which is shifted to slightly lower voltages in subsequent sweeps (see Figure $4 b$, insert). The reduction current however increases in the following sweeps which suggests the formation of a poor passivation layer in $1 \mathrm{M} \mathrm{NaPF}_{6}$ in the TMP electrolyte.

The $0.5 \mathrm{M} \mathrm{NaBOB}$ in the TMP electrolyte was further evaluated in two-electrode sodium-ion full cells consisting of a hard carbon anode and a Prussian white cathode. The results in Figure 5a,b show that the NaBOB-TMP electrolyte provides superior cycling performance compared to the $\mathrm{NaPF}_{6}-\mathrm{TMP}$ electrolyte with Coulombic efficiency (CE) at $75 \%$ compared to that of $55 \%$ for $\mathrm{NaPF}_{6}$ for the first cycle. The additive-free $\mathrm{NaBOB}-\mathrm{TMP}$ electrolyte enables stable cycling while the additive-free $\mathrm{NaPF}_{6}-\mathrm{TMP}$, in accordance with the literature, ${ }^{33}$ has very poor performance and only maintains 31 $\mathrm{mAh} \mathrm{g}^{-1}$ at the 10th cycle compared to the $108 \mathrm{~mA} \mathrm{~h} \mathrm{~g}^{-1}$ of NaBOB-TMP. The SEI formation in the NaBOB-based electrolyte was observed between 1.5 and $2.5 \mathrm{~V}$ during the first charge, and the early $\mathrm{NaBOB}$ decomposition into carbonates stabilize the TMP solvent while $\mathrm{NaPF}_{6}$ clearly suffers from suboptimal passivation.

Figure 5c,d displays the voltage profile of hard carbon anode and the Prussian white cathode individually versus the reference electrode in a three-electrode cell. The reference electrode was also consisted of Prussian white, as an alternative to the unreliable Na metal electrode. ${ }^{34}$ (Note that hard carbon half-cells became unstable when using sodium-metal counter electrodes which yielded no useful data. The PW half-cells using $\mathrm{NaBOB}-\mathrm{TMP}$ suffered from high initial polarization while $\mathrm{NaPF}_{6}-\mathrm{TMP}$ suffered from rapid capacity fading which are likely due to parasitic reactions on the Na metal( see Figure S1 for the half-cell data). During the first charge, the reduction of $\mathrm{NaBOB}$ is clearly seen as a distinct plateau in the hard carbon potential during the initial stages (Figure $5 \mathrm{c}$ ) that is absent from the $\mathrm{NaPF}_{6}$ counterpart (Figure $5 \mathrm{~d}$ ). These results are in agreement with the $\mathrm{CV}$ data shown in Figure 4 indicating active contribution of $\mathrm{NaBOB}$ in the formation of SEI on hard carbon, and it is in agreement with the previous studies on $\mathrm{LiBOB}$ showing relatively high onset reduction potential for LiBOB. ${ }^{35}$

X-ray photoelectron spectroscopy (XPS) measurements were performed on hard carbon anodes after one full cycle in full-cells to compare the composition of SEI in the aforementioned electrolytes. Figure 6 displays the XPS spectra with peak assignments representing species present in the SEI on hard carbon and the relative atomic concentration. The $\mathrm{C}$ 1s spectrum of the pristine hard carbon sample contains two major peaks at 284.5 and $287 \mathrm{eV}$ representing hard carbon and $\mathrm{NaCMC}$ binder. The $\mathrm{C}-\mathrm{C}$ peak of hard carbon particles becomes almost invisible in the cycled electrodes, which indicates that the SEI formed on hard carbon is thicker than $\sim 10 \mathrm{~nm}$ (probing depth of in-house XPS with the Al K $\alpha$ source). The $\mathrm{C} 1 \mathrm{~s}$ and $\mathrm{O} 1 \mathrm{~s}$ spectra of cycled electrodes reveal that the composition of SEI differs with the chemistry of the electrolyte; the SEI in the cell with $\mathrm{NaBOB}-\mathrm{TMP}$ possesses hydrocarbons, $\mathrm{C}-\mathrm{O}$, and $-\mathrm{CO}_{3}$ species while being rich with $\mathrm{C}=\mathrm{O}$ and/or $\mathrm{O}-\mathrm{C}-\mathrm{O} .{ }^{36}$ However, the SEI in the cell with $\mathrm{NaPF}_{6}-\mathrm{TMP}$ contains more $\mathrm{C}-\mathrm{O}$ and $\mathrm{P}-\mathrm{O}$ species. The $\mathrm{C} 1 \mathrm{~s}$ spectrum of the cell with $\mathrm{NaPF}_{6}-\mathrm{TMP}$ also shows a small peak at a binding energy of $\sim 283 \mathrm{eV}$, indicating that the residual intercalated $\mathrm{Na}$ ions remained into the hard carbon framework even after full charge. ${ }^{37}$ This peak is absent in the cell with $\mathrm{NaBOB}-\mathrm{TMP}$ suggesting successful full desodiation of hard carbon at the end of the charge. The P 2p, F 1s, and B 1s spectra disclose that both $\mathrm{NaBOB}$ and $\mathrm{NaPF}_{6}$ salts as well as the TMP solvent contributed to SEI formation. The strong fluorine signal from $\mathrm{NaPF}_{6}-\mathrm{TMP}$ in the $\mathrm{F}$ 1s spectra shows that a part of phosphorus originates from $\mathrm{NaPF}_{6}$. However, TMP also participated in SEI formation as seen from the peak at $532 \mathrm{eV}$ in the $\mathrm{O} 1 \mathrm{~s}$ spectrum of the $\mathrm{NaPF}_{6}-\mathrm{TMP}$ sample, which is assigned to $\mathrm{C}-\mathrm{O}-\mathrm{P}$ and $\mathrm{P}=\mathrm{O}$ species as there is no carbonate formed according to the $\mathrm{C} 1 \mathrm{~s}$ spectrum. ${ }^{38}$ The $\mathrm{P} 2 \mathrm{p}$ spectrum of hard carbon from the cell with $\mathrm{NaBOB}-\mathrm{TMP}$ displays a small peak which is originated from TMP as there is no other source of phosphorus in this sample. All samples show one peak on $\mathrm{Na}$ 1s spectra, originated from the $\mathrm{NaCMC}$ binder and Na-containing SEI species.
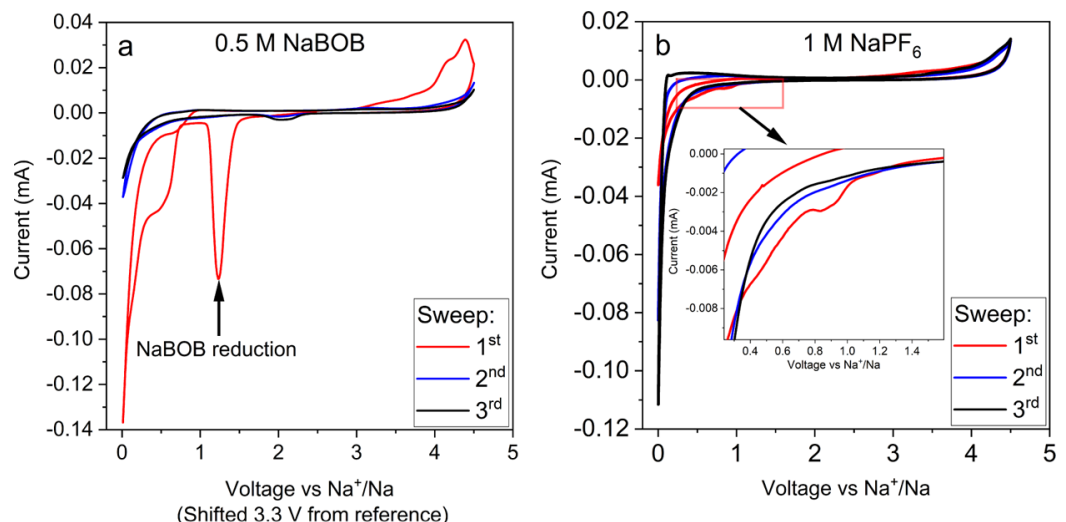

Figure 4. Cyclic voltammetry for $0.5 \mathrm{M} \mathrm{NaBOB}$ performed using a $\mathrm{PW}$ reference electrode (a) and $1 \mathrm{M} \mathrm{NaPF}_{6}$ using a sodium-metal counter electrode (b). The scan speed was set to $1 \mathrm{mV} \mathrm{s}^{-1}$ for both cells. 

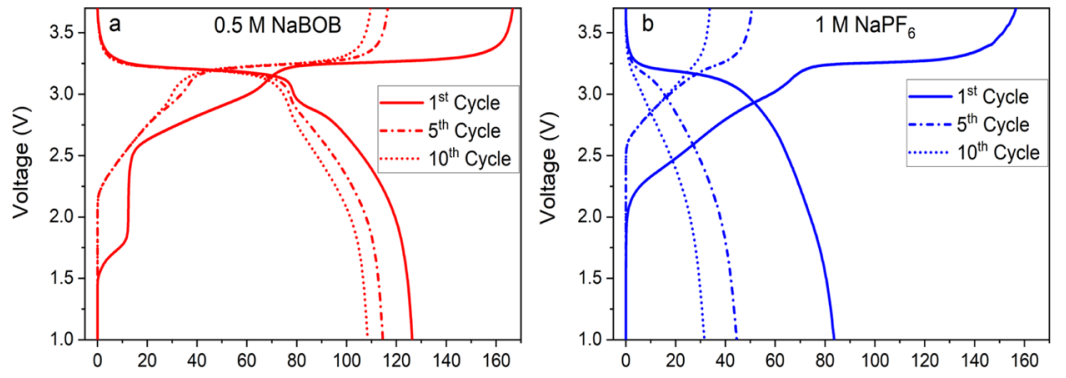

Capacity $\left(\mathrm{mAh} \mathrm{g}^{-1}\right)$ Capacity $\left(m A h g^{-1}\right)$
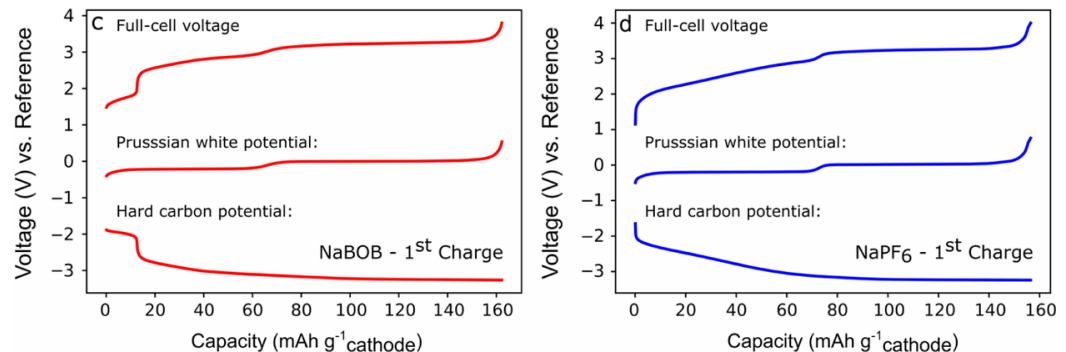

Figure 5. Galvanostatic cycling. 1st, 5th, and 10th charge-discharge curves in sodium-ion full-cells based on hard carbon anode and Prussian white cathode using $0.5 \mathrm{M} \mathrm{NaBOB}$ in the TMP electrolyte (a) and $1 \mathrm{M} \mathrm{NaPF}_{6}$ in the TMP electrolyte (b). First charge from three-electrode cells using $0.5 \mathrm{M} \mathrm{NaBOB}$ in $\mathrm{TMP}(\mathrm{c})$ and $1 \mathrm{M} \mathrm{NaPF}_{6}$ in the TMP electrolyte (d).

The electrochemical test and surface analysis presented above clearly shows the active role of $\mathrm{NaBOB}$ compared to $\mathrm{NaPF}_{6}$ in electrolytes based on TMP in the formation of SEI on hard carbon. However, despite demonstrating benefits over the $\mathrm{NaPF}_{6}$-based electrolyte, the additive-free $\mathrm{NaBOB}-\mathrm{TMP}$ still suffers from capacity fading and a relatively low $\mathrm{CE}$ of the first cycle (i.e. 75\%) which needs to be improved. It has previously been shown that additives can be used to further improve the first cycle CE and cycling stability. ${ }^{39-41}$ So, to test if the passivation of hard carbon could be improved in either system, we tested electrolytes containing both 5 and 10 vol \% vinylene carbonate (VC) in galvanostatic cycling (see Figure 7).

The addition of 5 vol \% VC to the NaBOB-TMP electrolyte increases the $\mathrm{CE}$ of the first cycle from 75 to $80 \%$, while the cells with a higher additive amount of $10 \mathrm{vol} \%$ VC shows somewhat an erratic behavior (Figure 7a). All our replicate cells showed good repeatability except the NaBOB 10 vol \% VC cells that showed considerable variation, with the first cycle $\mathrm{CE}$ values varying between 62 and $82 \%$, suggesting that this is a more sensitive system than the other compositions. Figure $7 \mathrm{c}$ shows that the decomposition plateau of $\mathrm{NaBOB}$ gradually disappears with an increasing addition of $\mathrm{VC}$, thus it appears that $\mathrm{VC}$ and $\mathrm{NaBOB}$ both participates in the SEI formation. The positive impact of $\mathrm{VC}$ becomes questionable at the higher $10 \mathrm{vol} \% \mathrm{VC}$ loading, as sometimes a second feature close to $2.4 \mathrm{~V}$ appears which indicates excessive VC breakdown with detrimental effects on the cell reversibility.

$\mathrm{VC}$ is however essential for stability in the $\mathrm{NaPF}_{6}-\mathrm{TMP}$ electrolyte as the capacity fading is substantially suppressed in VC-containing cells in Figure $7 \mathrm{~b}$. The addition of VC to the $\mathrm{NaPF}_{6}-\mathrm{TMP}$ system leads to appearance of a new feature in the voltage curve at $1.6 \mathrm{~V}$ during charge (Figure $7 \mathrm{~d}$, insert). This feature looks quite similar for both 5 and $10 \mathrm{vol} \%$ albeit with a slightly quicker voltage increase for $10 \% \mathrm{VC}$. The effect of VC on the initial Coulombic efficiencies is dramatic as the $\mathrm{CE}$ of the first cycle increases from $56 \%$ without VC, to almost
$84 \%$ for both electrolytes with $5 \%$ and 10 vol \% VC. This indicates that the passivation of the hard carbon anode occurs by means of $\mathrm{VC}$ rather than $\mathrm{NaPF}_{6}$ or TMP. It also appears that the process is less sensitive to the concentration of $\mathrm{VC}$ than $\mathrm{NaBOB}-\mathrm{TMP}$ as there no evidence of excessive additive decomposition even at $10 \mathrm{vol} \% \mathrm{VC}$. All of the best performing cells using VC with either $\mathrm{NaBOB}$ or $\mathrm{NaPF}_{6}$ display a rapid increase of the $\mathrm{CE}$ and reach above $96.5 \% \mathrm{CE}$ by the second cycle, as shown in Figure 7e. Note that the error bar disclose the variation in $\mathrm{CE}$ obtained from identical cells.

Extended cycling for all compositions was performed up to cycle 50. However, the capacity for the cells with $1 \mathrm{M} \mathrm{NaPF}_{6}$ in TMP without VC additive fades rapidly because of the unstable cycling, and thus, these results are omitted. Both 5 and $10 \mathrm{vol} \% \mathrm{VC}$ containing $1 \mathrm{M} \mathrm{NaPF}_{6}$ in TMP cells yield impressive cycling compared to their additive-free analogues (Figure 8a), confirming that VC continues to protect TMP against the hard carbon surface over time.

It appears that the long-term performance in the $0.5 \mathrm{M}$ $\mathrm{NaBOB}$ electrolytes also gains a long-term performance boost by addition of $\mathrm{VC}$, even if the improvement is not as dramatic as for $\mathrm{NaPF}_{6}$. Based on the results, a VC-based or at least a VC-containing passivation layer is preferable to the SEI formed by $\mathrm{NaBOB}$ alone as the $0.5 \mathrm{M} \mathrm{NaBOB}$ cells using 5 vol \% VC loading consistently show improved long-term capacity retention. It should be mentioned that the cell with $0.5 \mathrm{M}$ $\mathrm{NaBOB}$ in the TMP electrolyte with 10 vol \% VC often showed worse performance than the baseline additive-free electrolyte even though only the best performing cell is shown in Figure 8 with very impressive results (see Figure S2 in the Supporting Information for the results from all cells). These cycling performance in full cells is almost similar to our previous result on half-cells based Prussian white cathodes using 1.5 $\mathrm{M} \mathrm{NaPF}_{6}$ in dimethoxyethane. ${ }^{42}$

$\mathrm{NaBOB}$ salt is without doubt superior $\mathrm{NaPF}_{6}$ salt when used in TMP without additives; however, when additive-free $\mathrm{NaBOB}$ is compared to electrolytes that use $\mathrm{VC}$, it is generally true that the additive-free electrolyte loses more sodium 

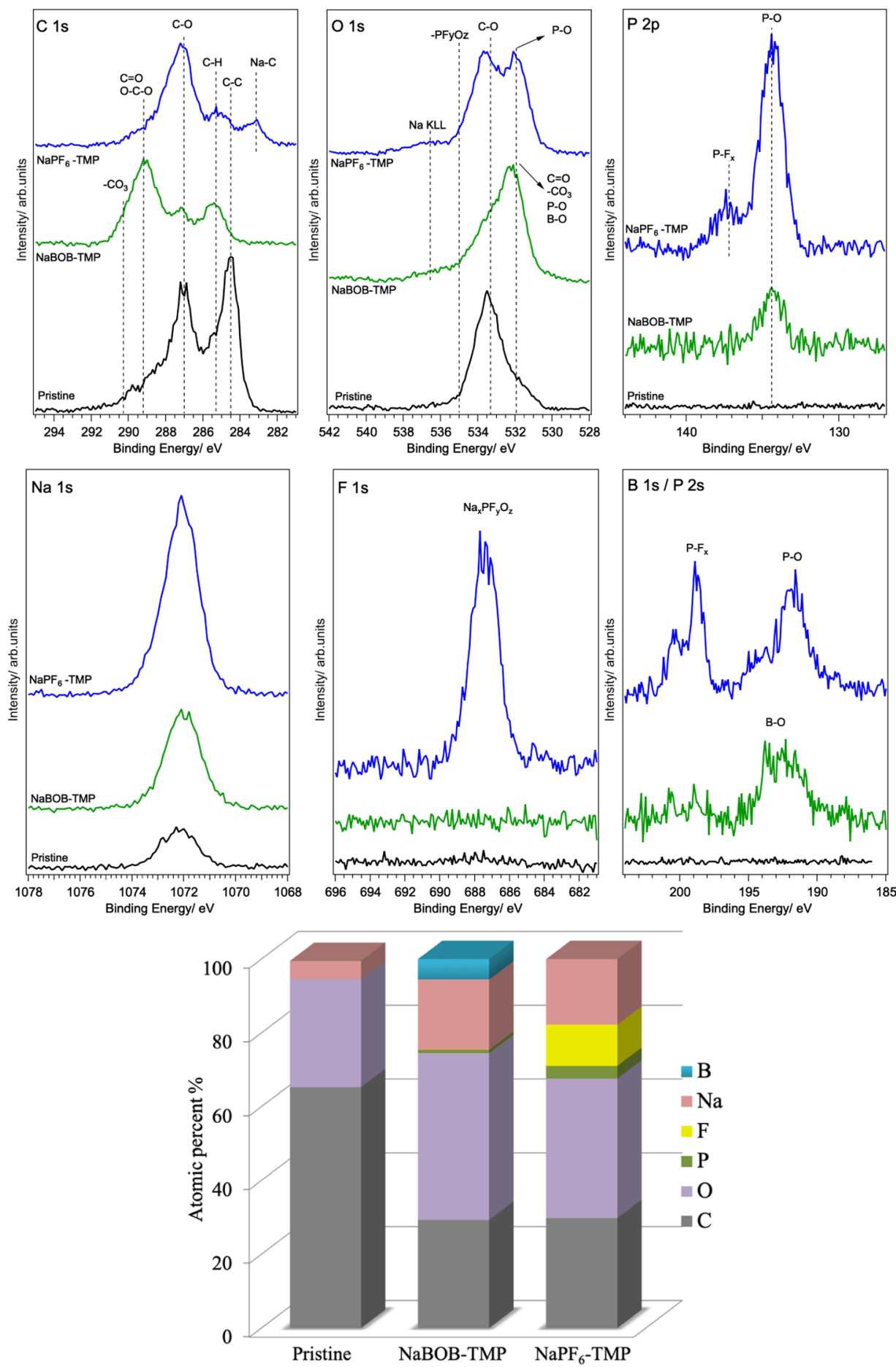

Figure 6. XPS spectra and relative atomic concentration of elements present on the surface of pristine and cycled hard carbon anodes after one cycle in HC-PW full-cells using electrolytes of $0.5 \mathrm{M} \mathrm{NaBOB}$ in TMP or $1 \mathrm{M} \mathrm{NaPF}_{6}$ in TMP.

inventory during the first cycle and suffers slightly lower CE in later cycles (see Figure 8).

The best performing cells of both TMP-NaBOB and TMP- $\mathrm{NaPF}_{6}$ using 5 and 10 vol \% VC all have $\mathrm{CE}$ values between 98.5 and $99 \%$ after 10 cycles, while additive-free TMP-NaBOB cycles above 97.5\% CE in cycles 4-50. Although longer cycling is required to reveal if the SEI is truly stable, the electrolytes tested here represent an important step toward practically viable nonflammable sodium-ion batteries.

\section{CONCLUSIONS}

The use of $\mathrm{NaBOB}$ as the electrolyte salt in sodium-ion batteries is for the first time shown here. A nonflammable and fluorine-free electrolyte based on NaBOB dissolved in TMP disclosed promising results in terms of the electrolyte ionic conductivity ( $5 \mathrm{mS} \mathrm{cm}^{-1}$ at room temperature) and electrochemical performance in sodium-ion full cells. Previous publications used high concentrations of salt or highly fluorinated solvents/additives to achieve high $\mathrm{CE}$ on hard carbon anodes. However, we have instead shown that $0.5 \mathrm{M}$ 

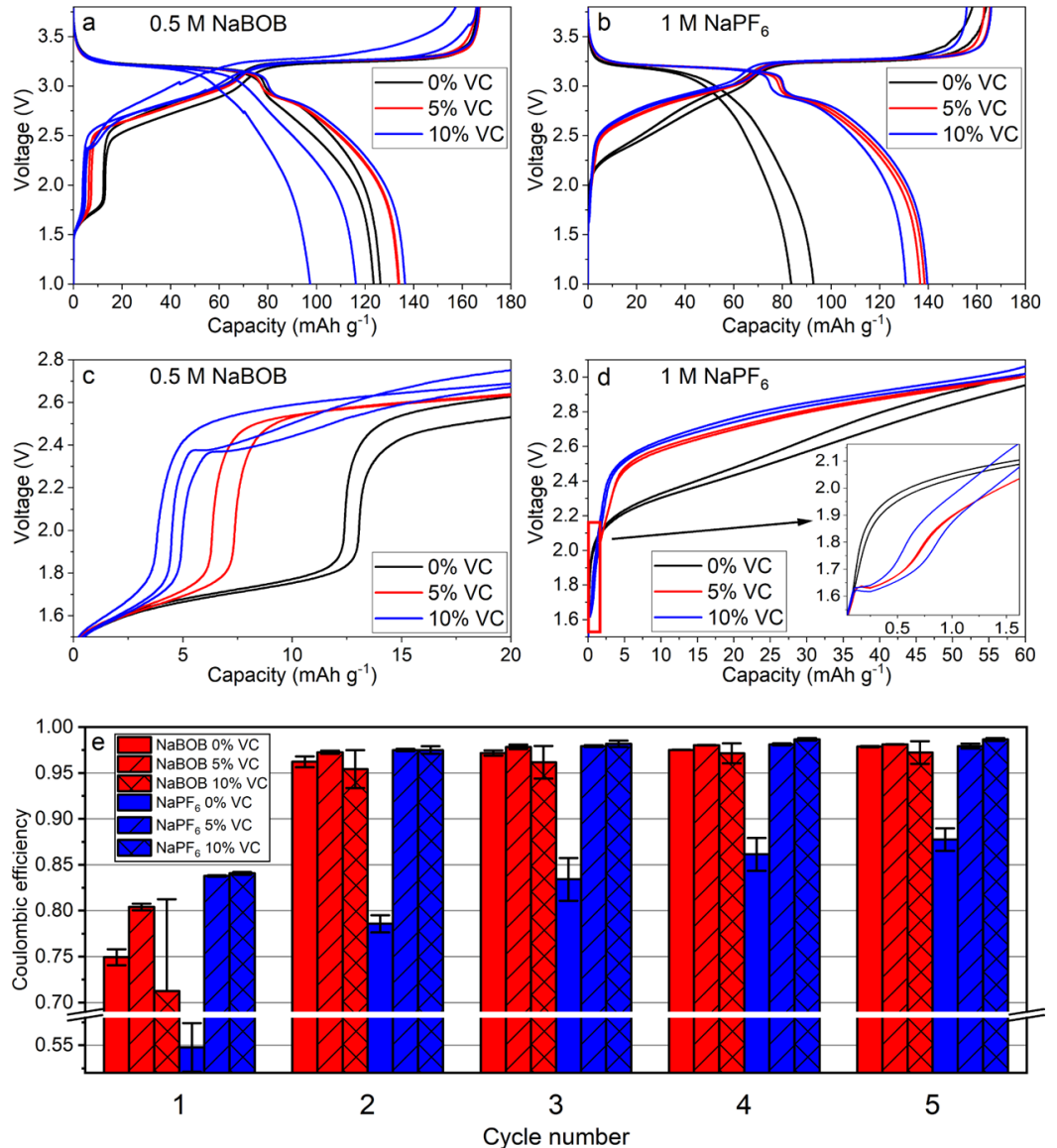

Figure 7. Galvanostatic cycling of sodium-ion full cells based on hard carbon anodes and Prussian white cathodes cycled with 0,5 , and 10 vol $\%$ VC additive $(\mathrm{a}, \mathrm{b})$ with zoomed in view of the SEI-forming region for $0.5 \mathrm{M} \mathrm{NaBOB}(\mathrm{c})$ and $1 \mathrm{M} \mathrm{NaPF}_{6}(\mathrm{~d})$. Cycling was performed between 3.8 and 1 $\mathrm{V}$, and two replicate cells are included for each electrolyte composition except $\mathrm{NaBOB} 10 \% \mathrm{VC}$ that has three replicates. CE of the first five cycles for $0.5 \mathrm{M} \mathrm{NaBOB}$ and $1 \mathrm{M} \mathrm{NaPF}_{6}$ (e). Coulombic efficiencies are averaged from the replicate cells with the standard deviation detonated by the error bars.
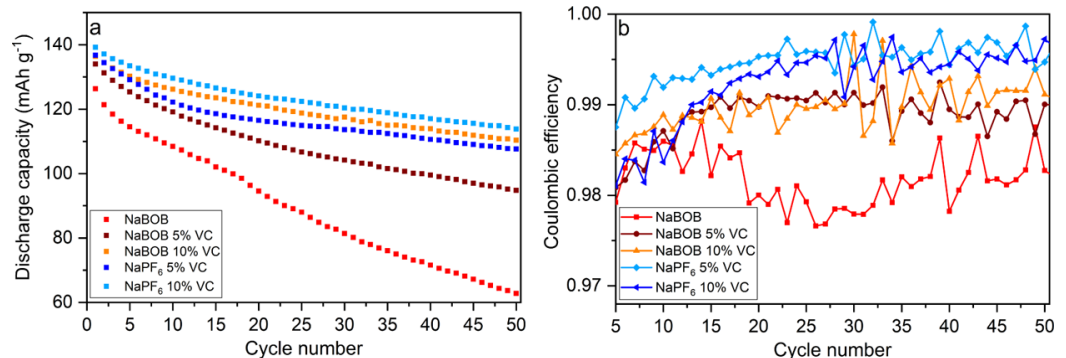

Figure 8. Extended galvanostatic cycling at $30 \mathrm{~mA} \mathrm{~g}^{-1}$. Results from the best performing cells of all replicates, showing specific discharge capacity based on the cathode mass (a) and CE for the same cells (b).

$\mathrm{NaBOB}$ in TMP enables relatively high $\mathrm{CE}$ in hard carbonbased full-cell sodium-ion cells. The proposed electrolyte can of course be further optimized using electrolyte additives to achieve higher initial CEs and an improved cycle life. As one example, VC has here been shown to improve the electrochemical performance of full-cell sodium batteries using the studied electrolyte compositions. Overall, this means that high energy-density cells ( $>250 \mathrm{~W} \mathrm{~h} \mathrm{~kg}^{-1}$ based on active materials) built from low-cost and abundant materials can be cycled at Columbic efficiencies above $99 \%$. This is in cells with electrolytes that cannot burn using a solvent that freezes at a low $-46{ }^{\circ} \mathrm{C}$, without the environmental and health aspects of using highly fluorinated compounds. In short, this work is a promising step to remove most of the problems that state-ofthe-art electrolytes suffer from.

\section{EXPERIMENTAL SECTION}

Materials. TMP (99\%) was purchased from Merck and was produced by Acros. TMP was dried over freshly activated molecular sieves before use in electrolytes. $\mathrm{NaBOB}$ was synthesized using the method stated by Zavalij et al. ${ }^{19}$ with the added step of recrystallizing the synthesized $\mathrm{NaBOB}$ in $\mathrm{TMP}$ before vacuum drying at $100{ }^{\circ} \mathrm{C}$ for more than $12 \mathrm{~h}$ to make sure that the salt was sufficiently dry for use in an electrolyte. The resulting salt was characterized by X-ray diffraction and elemental analysis. VC was obtained from Gotion Inc. and used as received. Hard carbon anode powder was obtained from a 
commercial source and used as received while Altris $\mathrm{AB}$ supplied the Prussian white $\left(\mathrm{Na}_{x} \mathrm{Fe}\left[\mathrm{Fe}(\mathrm{CN})_{6}\right]\right)(x>1.8)$ cathode powder.

Analytical Methods. Elemental analysis was performed by Medac LTD., and two equivalent samples were analyzed twice each using CHN combustion analysis \& ICP-OES (see supplemental for full report). Conductivity was performed using a Mettler Toledo SevenGo Duo pro $\mathrm{pH} / \mathrm{ORP} / \mathrm{Ion} /$ Conductivity meter SG78 with an InLab 738ISM probe under argon in a glove box $\left(\mathrm{O}_{2}, \mathrm{H}_{2} \mathrm{O} 1 \mathrm{ppm}\right)$. Thermogravimetric analysis was performed on a TA Instruments TGA Q500 under nitrogen flow between room temperature and 600 ${ }^{\circ} \mathrm{C}$ with $5{ }^{\circ} \mathrm{C} \mathrm{min}{ }^{-1}$ heat rate. Powder $\mathrm{X}$-ray diffraction measurements were performed in the transmission mode on a Stoe \& Cie $\mathrm{GmbH}$ Stadi X-ray powder diffractometer equipped with a $\mathrm{Ge}$ monochromator (single-wavelength $\mathrm{Cu} \mathrm{K} \alpha_{1}$ ). A Mythen $1 \mathrm{~K} \mathrm{Si} \mathrm{strip}$ detector was operated in the sweeping mode with an angular resolution of $2 \theta=0.015^{\circ}$. Full details of the Rietveld refinement are available in the Supporting Information.

Electrolyte Preparation. $\mathrm{NaBOB}-\mathrm{TMP}$ mixtures with the concentrations $0.1,0.2,0.3,0.4,0.5$, and $0.6 \mathrm{~mol} \mathrm{~L}^{-1}$ were prepared in volumetric flasks. The solutions of $0.3,0.4,0.5 \mathrm{M}$, and above required heating $\left(\sim 60^{\circ} \mathrm{C}\right)$ to dissolve, while $0.6 \mathrm{M}$ solution remained turbid even after heating. The preparation and heating were performed under argon in a glove box using a heater/stirrer hotplate.

Flammability Test. The flammability tests were performed on electrolytes by soaking a strip of glass fiber in the electrolyte and exposing it to a butane gas flame in a fume hood. The tests were recorded using a mobile phone camera, and pictures and times were collected from the recordings.

Electrode Preparation and Cell Assembly. For Prussian white cathodes, the active material, super C65 (C·NERGY) carbon additive, and $\mathrm{NaCMC}$ binder (Sigma-Aldrich) were mixed in a 85:10:5 ratio by weight, respectively, and to this, approximately $5 \mathrm{~mL}$ distilled water per gram of active material was added before mixing for $1 \mathrm{~h}$ in a planetary ball mill. The slurry was coated using an applicator rod with $150 \mu \mathrm{m}$ gap onto a $20 \mu \mathrm{m}$ carbon-coated aluminum foil. Hard carbon anodes were also prepared on a carbon-coated aluminum foil using a 95:5 ratio by weight of hard carbon and the $\mathrm{NaCMC}$ binder with approximately $6 \mathrm{~mL}$ distilled water per gram of active material before mixing for $1 \mathrm{~h}$ using a planetary ball mill and coating with a $100 \mu \mathrm{m}$ gap applicator rod. The anodes and cathodes were both punched into $20 \mathrm{~mm}$ in diameter discs with a mass loading of approximately $1.9 \mathrm{mg}$ $\mathrm{cm}^{-2}$ for $\mathrm{PW}$ and $1.1 \mathrm{mg} \mathrm{cm}{ }^{-2}$ for hard carbon electrodes. The electrodes were dried at $140{ }^{\circ} \mathrm{C}$ under vacuum overnight. The cells for galvanostatic cycling used $30 \mathrm{~mm}$ diameter Dreamweaver gold (polyaramid fiber) separators and $100 \mu \mathrm{L}$ electrolyte, while the halfcells, three-electrode cells, and cells for cyclic voltammetry used 30 $\mathrm{mm}$ diameter Whatman glass-fiber separators and $200 \mu \mathrm{L}$ electrolyte. All types were assembled in pouch-cells that were sealed at 2 mbar vacuum. All cell assembly and electrode drying were performed in an argon glove box with $\mathrm{O}_{2}$ and $\mathrm{H}_{2} \mathrm{O}<1 \mathrm{ppm}$.

Electrochemical Methods. Galvanostatic cycling for twoelectrode cells was performed at $30 \mathrm{~mA} \mathrm{~g}^{-1}$ (corresponding to 60 $\mu \mathrm{A} \mathrm{cm}^{-2}$ ) between 1 and $3.8 \mathrm{~V}$ on a Neware BTS4000 galvanostat while three-electrode cells were cycled on a Biologic MPG2 potentiostat between 1 and $4 \mathrm{~V}$.

Cyclic voltammetry was performed on a Biologic MPG2 potentiostat. The measurements were performed in pouch cells with two-electrode cells using a metallic sodium (Aldrich 99.9\%) counter electrode or three-electrode cells with a Prussian white counter electrode and a Prussian white reference electrode desodiated to $3.3 \mathrm{~V}$ versus $\mathrm{Na}^{+} / \mathrm{Na}$. Both cell types used a carbon-coated aluminum foil working electrodes, and scans were performed using $1 \mathrm{mV} \mathrm{s}^{-1}$ scan speed. Scans started at OCV and were performed between 0 and $4.5 \mathrm{~V}$ versus $\mathrm{Na}^{+} / \mathrm{Na}$.

XPS Characterization. XPS measurements of cycled electrodes were carried out using a PerkinElmer PHI 5500 system with an excitation photon energy of $1486.6 \mathrm{eV}$. The samples were prepared in an Ar-filled glove box, where cycled cells were opened and rinsed with TMP. Thereafter, the washed samples were gently dried under vacuum over night before being mounted on a sample plate and sealed in a transfer cup. This made it possible to transfer the samples into the XPS without air exposure. The hard carbon electrodes were energy calibrated against the carbon black peak set to 284.4 when visible and secondary carbon peaks when the substrate peak was obscured.

\section{ASSOCIATED CONTENT}

\section{Supporting Information}

The Supporting Information is available free of charge at https://pubs.acs.org/doi/10.1021/acsaem.0c00522.

$\mathrm{X}$-ray diffraction and Rietveld refinement of synthesized $\mathrm{NaBOB}$ salt, refined unit cell parameters, galvanostatic cycling of Prussian white half-cells using 0.5 M NaBOB in TMP and $1 \mathrm{M} \mathrm{NaPF}_{6}$ electrolytes, and discharge capacity versus cycle number for all the replicate cells (PDF)

Flammability test of $0.5 \mathrm{M} \mathrm{NaBOB}$ in the TMP electrolyte (MP4)

Flammability test of the TMP solvent (MP4)

Flammability test of the PC solvent (MP4)

\section{AUTHOR INFORMATION}

\section{Corresponding Author}

Reza Younesi - Department of Chemistry-Ångström Laboratory, Uppsala University, SE-75121 Uppsala, Sweden; 이이.org/ 0000-0003-2538-8104; Email: reza.younesi@kemi.uu.se

\section{Authors}

Ronnie Mogensen - Department of Chemistry-Ångström Laboratory, Uppsala University, SE-75121 Uppsala, Sweden

Simon Colbin - Department of Chemistry-Ångström Laboratory, Uppsala University, SE-75121 Uppsala, Sweden

Ashok Sreekumar Menon - Department of ChemistryÅngström Laboratory, Uppsala University, SE-75121 Uppsala, Sweden; (i) orcid.org/0000-0001-8148-8615

Erik Björklund - Department of Chemistry-Ångstrom Laboratory, Uppsala University, SE-75121 Uppsala, Sweden

Complete contact information is available at:

https://pubs.acs.org/10.1021/acsaem.0c00522

\section{Notes}

The authors declare the following competing financial interest(s): The Prussian white powder used as positive electrode material in this study is a commercial product provided by ALTRIS AB, a company co-founded by R.M and R.Y. The other authors in this paper declare to have no competing interests.

\section{ACKNOWLEDGMENTS}

We would like to thank Dr. Andy Naylor for proof reading and scientific discussion. Authors would like to acknowledge the financial support by the ÅForsk Foundation via the grant no. 19-705 and by STandUP for Energy. A.S.M would like to acknowledge the Swedish Foundation for Strategic Research (SSF) for the financial support through the Swedish national graduate school in neutron scattering (SwedNess).

\section{REFERENCES}

(1) Vaalma, C.; Buchholz, D.; Weil, M.; Passerini, S. A Cost and Resource Analysis of Sodium-Ion Batteries. Nat. Rev. Mater. 2018, 3, 18013. 
(2) Huang, Y.; Zheng, Y.; Li, X.; Adams, F.; Luo, W.; Huang, Y.; Hu, L. Electrode Materials of Sodium-Ion Batteries toward Practical Application. ACS Energy Lett. 2018, 3, 1604-1612.

(3) Liu, T.; Zhang, Y.; Jiang, Z.; Zeng, X.; Ji, J.; Li, Z.; Gao, X.; Sun, M.; Lin, Z.; Ling, M.; Zheng, J.; Liang, C. Exploring Competitive Features of Stationary Sodium Ion Batteries for Electrochemical Energy Storage. Energy Environ. Sci. 2019, 12, 1512-1533.

(4) Hwang, J.-Y.; Myung, S.-T.; Sun, Y.-K. Sodium-Ion Batteries: Present and Future. Chem. Soc. Rev. 2017, 46, 3529-3614.

(5) Huang, Y.; Zhao, L.; Li, L.; Xie, M.; Wu, F.; Chen, R. Electrolytes and Electrolyte/Electrode Interfaces in Sodium-Ion Batteries: From Scientific Research to Practical Application. Adv. Mater. 2019, 31, 1808393.

(6) Chawla, N.; Bharti, N.; Singh, S. Recent Advances in NonFlammable Electrolytes for Safer Lithium-Ion Batteries. Batteries 2019, 5, 19.

(7) Ponrouch, A.; Monti, D.; Boschin, A.; Steen, B.; Johansson, P.; Palacín, M. R. Non-Aqueous Electrolytes for Sodium-Ion Batteries. J. Mater. Chem. A 2015, 3, 22-42.

(8) Younesi, R.; Veith, G. M.; Johansson, P.; Edström, K.; Vegge, T. Lithium Salts for Advanced Lithium Batteries: Li-Metal, Li-O2, and Li-S. Energy Environ. Sci. 2015, 8, 1905-1922.

(9) Xu, W.; Angell, C. A. Weakly Coordinating Anions, and the Exceptional Conductivity of Their Nonaqueous Solutions. Electrochem. Solid-State Lett. 2001, 4, No. E1.

(10) Xu, K.; Zhang, S.; Jow, T. R.; Xu, W.; Angell, C. A. LiBOB as Salt for Lithium-Ion Batteries:A Possible Solution for High Temperature Operation. Electrochem. Solid-State Lett. 2002, 5, A26.

(11) Xu, K.; Zhang, S. S.; Lee, U.; Allen, J. L.; Jow, T. R. LiBOB: Is It an Alternative Salt for Lithium Ion Chemistry? J. Power Sources 2005, 146, 79-85.

(12) Yu, B.-T.; Qiu, W.-H.; Li, F.-S.; Cheng, L. Comparison of the Electrochemical Properties of LiBOB and LiPF6 in Electrolytes for LiMn2O4/Li Cells. J. Power Sources 2007, 166, 499-502.

(13) Xu, K.; Zhang, S.; Poese, B. A.; Jow, T. R. Lithium Bis(Oxalato)Borate Stabilizes Graphite Anode in Propylene Carbonate. Electrochem. Solid-State Lett. 2002, 5, A259.

(14) Feng, J. K.; Ai, X. P.; Cao, Y. L.; Yang, H. X. Possible Use of Non-Flammable Phosphonate Ethers as Pure Electrolyte Solvent for Lithium Batteries. J. Power Sources 2008, 177, 194-198.

(15) Yu, B.-T.; Qiu, W.-H.; Li, F.-S.; Xu, G.-X. The Electrochemical Characterization of Lithium Bis(Oxalato)Borate Synthesized by a Novel Method. Electrochem. Solid-State Lett. 2006, 9, A1.

(16) Xu, K.; Zhang, S.; Jow, T. R. LiBOB as Additive in LiPF6-Based Lithium Ion Electrolytes. Electrochem. Solid-State Lett. 2005, 8, A365.

(17) Zhang, S. S.; Xu, K.; Jow, T. R. Enhanced Performance of LiIon Cell with LiBF4-PC Based Electrolyte by Addition of Small Amount of LiBOB. J. Power Sources 2006, 156, 629-633.

(18) Zeng, Z.; Murugesan, V.; Han, K. S.; Jiang, X.; Cao, Y.; Xiao, L.; Ai, X.; Yang, H.; Zhang, J.-G.; Sushko, M. L.; Liu, J. Non-Flammable Electrolytes with High Salt-to-Solvent Ratios for Li-Ion and Li-Metal Batteries. Nat. Energy 2018, 3, 674-681.

(19) Zavalij, P. Y.; Yang, S.; Whittingham, M. S. Structures of Potassium, Sodium and Lithium Bis(Oxalato)Borate Salts from Powder Diffraction Data. Acta Crystallogr., Sect. B: Struct. Sci. 2003, 59, 753-759.

(20) Chen, J.; Huang, Z.; Wang, C.; Porter, S.; Wang, B.; Lie, W.; Liu, H. K. Sodium-Difluoro(Oxalato)Borate (NaDFOB): A New Electrolyte Salt for Na-Ion Batteries. Chem. Commun. 2015, 51, 9809-9812.

(21) Wang, L.; Han, W.; Ge, C.; Zhang, R.; Bai, Y.; Zhang, X. Functionalized Carboxyl Carbon/NaBOB Composite as Highly Conductive Electrolyte for Sodium Ion Batteries. ChemistrySelect 2018, 3, 9293-9300.

(22) Yao, X. L.; Xie, S.; Chen, C. H.; Wang, Q. S.; Sun, J. H.; Li, Y. L.; Lu, S. X. Comparative Study of Trimethyl Phosphite and Trimethyl Phosphate as Electrolyte Additives in Lithium Ion Batteries. J. Power Sources 2005, 144, 170-175.
(23) Wang, X.; Yasukawa, E.; Kasuya, S. Nonflammable Trimethyl Phosphate Solvent-Containing Electrolytes for Lithium-Ion Batteries: II. The Use of an Amorphous Carbon Anode. J. Electrochem. Soc. 2001, 148, A1066.

(24) Zeng, Z.; Jiang, X.; Li, R.; Yuan, D.; Ai, X.; Yang, H.; Cao, Y. A Safer Sodium-Ion Battery Based on Nonflammable Organic Phosphate Electrolyte. Adv. Sci. 2016, 3, 1600066.

(25) Zhao, X. M.; Yan, Y. W.; Ren, X. X.; Chen, L.; Xu, S. D.; Liu, S. B.; Wang, X. M.; Zhang, D. Trimethyl Phosphate for Nonflammable Carbonate-Based Electrolytes for Safer Room-Temperature SodiumSulfur Batteries. ChemElectroChem 2019, 6, 1229-1234.

(26) Wang, X.; Yamada, C.; Naito, H.; Segami, G.; Kibe, K. HighConcentration Trimethyl Phosphate-Based Nonflammable Electrolytes with Improved Charge-Discharge Performance of a Graphite Anode for Lithium-Ion Cells. J. Electrochem. Soc. 2006, 153, A135.

(27) Wang, J.; Yamada, Y.; Sodeyama, K.; Watanabe, E.; Takada, K.; Tateyama, Y.; Yamada, A. Fire-Extinguishing Organic Electrolytes for Safe Batteries. Nat. Energy 2018, 3, 22-29.

(28) Shi, P.; Zheng, H.; Liang, X.; Sun, Y.; Cheng, S.; Chen, C.; Xiang, H. A Highly Concentrated Phosphate-Based Electrolyte for High-Safety Rechargeable Lithium Batteries. Chem. Commun. 2018, 54, 4453-4456.

(29) Xiao, L.; Zeng, Z.; Liu, X.; Fang, Y.; Jiang, X.; Shao, Y.; Zhuang, L.; Ai, X.; Yang, H.; Cao, Y.; Liu, J. Stable Li Metal Anode with "IonSolvent-Coordinated" Nonflammable Electrolyte for Safe Li Metal Batteries. ACS Energy Lett. 2019, 4, 483-488.

(30) Ehlert, T. C.; Hsia, M.-M. Thermal Decomposition of Alkali Metal Hexafluorophosphates. J. Chem. Eng. Data 1972, 17, 18-21.

(31) Goodenough, J. B.; Kim, Y. Challenges for Rechargeable Li Batteries. Chem. Mater. 2010, 22, 587-603.

(32) Dahbi, M.; Yabuuchi, N.; Fukunishi, M.; Kubota, K.; Chihara, K.; Tokiwa, K.; Yu, X.-f.; Ushiyama, H.; Yamashita, K.; Son, J.-Y.; Cui, Y.-T.; Oji, H.; Komaba, S. Black Phosphorus as a High-Capacity, High-Capability Negative Electrode for Sodium-Ion Batteries: Investigation of the Electrode/Electrolyte Interface. Chem. Mater. 2016, 28, 1625-1635.

(33) Zeng, Z.; Jiang, X.; Li, R.; Yuan, D.; Ai, X.; Yang, H.; Cao, Y. A Safer Sodium-Ion Battery Based on Nonflammable Organic Phosphate Electrolyte. Adv. Sci. 2016, 3, 1600066.

(34) Dugas, R.; Forero-Saboya, J. D.; Ponrouch, A. Methods and Protocols for Reliable Electrochemical Testing in Post-Li Batteries ( $\mathrm{Na}, \mathrm{K}, \mathrm{Mg}$, and $\mathrm{Ca}$ ). Chem. Mater. 2019, 31, 8613-8628.

(35) Xu, K.; Lee, U.; Zhang, S.; Allen, J. L.; Jow, T. R. Graphite/ Electrolyte Interface Formed in LiBOB-Based Electrolytes. Electrochem. Solid-State Lett. 2004, 7, A273.

(36) Mogensen, R.; Maibach, J.; Naylor, A. J.; Younesi, R. Capacity Fading Mechanism of Tin Phosphide Anodes in Sodium-Ion Batteries. Dalton Trans. 2018, 47, 10752-10758.

(37) Carboni, M.; Manzi, J.; Armstrong, A. R.; Billaud, J.; Brutti, S.; Younesi, R. Analysis of the Solid Electrolyte Interphase on Hard Carbon Electrodes in Sodium-Ion Batteries. ChemElectroChem 2019, 6, 1745-1753.

(38) Spori, D. M.; Venkataraman, N. V.; Tosatti, S. G. P.; Durmaz, F.; Spencer, N. D.; Zürcher, S. Influence of Alkyl Chain Length on Phosphate Self-Assembled Monolayers. Langmuir 2007, 23, 80538060.

(39) Eshetu, G. G.; Martinez-Ibañez, M.; Sánchez-Diez, E.; Gracia, I.; Li, C.; Rodriguez-Martinez, L. M.; Rojo, T.; Zhang, H.; Armand, M. Electrolyte Additives for Room-Temperature, Sodium-Based, Rechargeable Batteries. Chem.-Asian J. 2018, 13, 2770-2780.

(40) Komaba, S.; Ishikawa, T.; Yabuuchi, N.; Murata, W.; Ito, A.; Ohsawa, Y. Fluorinated Ethylene Carbonate as Electrolyte Additive for Rechargeable Na Batteries. ACS Appl. Mater. Interfaces 2011, 3, $4165-4168$.

(41) Che, H.; Liu, J.; Wang, H.; Wang, X.; Zhang, S. S.; Liao, X.-Z.; Ma, Z.-F. Rubidium and Cesium Ions as Electrolyte Additive for Improving Performance of Hard Carbon Anode in Sodium-Ion Battery. Electrochem. Commun. 2017, 83, 20-23. 
(42) Brant, W. R.; Mogensen, R.; Colbin, S.; Ojwang, D. O.; Schmid, S.; Häggström, L.; Ericsson, T.; Jaworski, A.; Pell, A. J.; Younesi, R. Selective Control of Composition in Prussian White for Enhanced Material Properties. Chem. Mater. 2019, 31, 7203-7211. 